\title{
Review
}

\section{Mitochondrial Antioxidant Enzymes and Endurance Exercise-induced Cardioprotection against Ischemia-Reperfusion Injury}

\author{
Insu Kwon, PhD; Yongchul Jang, PhD; Wankeun Song, MS; Mark H. Roltsch, PhD; Youngil Lee, PhD* \\ Department of Exercise Science and Community Health, University of West Florida, Pensacola, FL 325 I 4, USA

\section{*Corresponding author} \\ Youngil Lee, $\mathrm{PhD}$ \\ Molecular and Cellular Exercise Physiology Laboratory, Department of Exercise Science and Community Health, Usha Kundu College of Health University of \\ West Florida, I 1000 University Pkwy, Bldg. 72, Pensacola, Florida 325 I4, USA;Tel. I-850-474-2596; Fax: I-850-474-2596; E-mail: ylee@uwf.edu
}

\section{Article information}

Received: March 8 ${ }^{\text {th }}$,2018; Revised: March 20

\section{Cite this article}

Kwon I, Jang Y, Song W, Roltsch MH, Lee Y. Mitochondrial antioxidant enzymes and endurance exercise-induced cardioprotection against ischemia-reperfusion injury. Sport Exerc Med Open J. 2018; 4(I): 9-15. doi: 10.17140/SEMOJ-4-155

\section{ABSTRACT}

Coronary artery disease (CAD) is the most common cause of myocardial injuries induced by prolonged cessation of blood flow (ischemia) to cardiac myocytes due to atherosclerosis. For several decades, many clinical trials have been applied to protect hearts against ischemia and reperfusion (I/R) injuries, but failed to show significant improvement in the restoration of cardiac function. By contrast, growing evidence has shown that a non-pharmacological strategy, endurance exercise, provides cardioprotection against ischemic myocardial injuries. Despite the prominent cardioprotective benefit; however, the exact molecular and cellular protective mechanisms remain an exciting issue. Nonetheless, given that excess production of reactive oxygen species (ROS) is a primary mediator of cardiac injuries caused by an $\mathrm{I} / \mathrm{R}$ insult, improved myocardial antioxidant capacity in response to endurance exercise has been suggested to be a key mechanism against I/R injuries, in particular, Therefore, this review will focus the role of endurance exercise-induced improvement in myocardial antioxidants in cardioprotection against I/R induced myocardial infarction.

\section{Keywords}

Endurance exercise; Mitochondria; Antioxidant enzymes; Ischemia reperfusion; Cardioprotection.

\section{Abbreviations}

CAD: Coronary Artery Diseases; mPTP: mitochondrial Permeability Transition Pore; AIF: Apoptosis Inducing Factor; GPX: Glutathione Peroxidase; CAT: Catalase; PRX III: Peroxiredoxin III; ROS: Reactive Oxygen Species; GSH: Glutathione; GSSG: Oxidized Glutathione; TRX II: Thioredoxin II; NRF2: Nuclear Erythroid-2 Like Factor-2.

\section{INTRODUCTION}

$\mathrm{T}$ The heart is one of the most dynamic organs in our body since it constantly pumps the blood through the whole body. To continuously fulfil this critical task, cardiac myocytes should receive suitable amounts of oxygen and nutrients through coronary arteries; however, if blood flow to coronary arteries is significantly obstructed due to atherosclerosis (a disease of the arteries caused by an increase in the deposition of plaques of fatty material on the inner walls of arteries), cardiomyocytes undergo ischemia, leading to myocardial infarction. Indeed, prolonged blockage of the blood flow (chronic ischemia) due to coronary artery diseases (CAD) causes the massive death of cardiac myocytes.

The degree of myocardial injuries varies depending upon the duration of ischemia, but beyond 20 minutes results in irreversible myocyte damage, ${ }^{1}$ but a timely restoration of the obstructed blood flow (reperfusion) can ameliorate levels of cell death. Nevertheless, this salvage procedure (i.e., reperfusion by angioplasty) still contributes to significant cell death and to formation of fibrosis, thus gradually leading to heart failure. ${ }^{2-5}$ Therefore, ischemia and reperfusion $(\mathrm{I} / \mathrm{R})$-induced myocardial cell death is a major risk fac- 
tor for heart failure and become the leading cause of adult death in U.S. ${ }^{6,7}$

Despite three decades of incessant pharmacological trials to mitigate I/R-induced myocardial injuries in the clinical setting, currently, satisfactory therapy is still greatly lacking, and thus there is an urgent need to devise potent therapeutic strategies. In this regard, endurance exercise has been suggested to remarkably reduce $\mathrm{I} / \mathrm{R}$-induced myocardial infarction. However, exact mechanisms responsible for exercise-induced cardioprotection against an $\mathrm{I} / \mathrm{R}$ insult remain poorly understood and elusive.

In normal resting mammalian cells, about $0.4 \sim 4 \%$ of the consumed oxygen in the mitochondria is released as reactive oxygen species (ROS). ${ }^{8}$ However, their levels vastly elevate during an $\mathrm{I} / \mathrm{R}$ episode and contribute to I/R injury, which can lead to myocardial cell death. ${ }^{1,9-14}$ Given that regular endurance exercise has been reported to improve antioxidative capacity, it seems reasonable to presume that the enhanced antioxidative capacity may be an essential element for cardioprotection. Therefore, this review will provide basic information about how ROS causes cellular damages during an I/R insult, describe current molecular mechanisms of antioxidative network systems working against ROS, and present cardioprotective roles of endurance exercise-induced improvement of antioxidant capacity.

\section{MITOCHONDRIAL ROS AND APOPTOSIS}

Free radicals are chemically reactive molecules due to an unpaired electron in the outer orbital ${ }^{11}$ and thus become origins of ROS. For example, a superoxide anion is an oxygen-driven radical produced as a result of the univalent reduction of molecular oxygen. It's production leads to the formation of many other ROS including hydrogen peroxide, $\mathrm{H}_{2} \mathrm{O}_{2}$; hydroxyl radical, $\mathrm{OH}$; and peroxynitrite, $\mathrm{ONOO}^{-11,15,16}$ It has been reported that mitochondrion in mammalian cells is the main locus that generates superoxide anions due to an electron leaked from complex I and III of mitochondrial electron transport chain. ${ }^{17-21}$ Since superoxide radicals are charged molecules, they have less chance to cross the mitochondrial membranes; thus, if not scavenged, superoxide radicals cause mitochondrial membrane lipid peroxidation and protein oxidation in electron transport chain complexes as well as Krebs cycle enzymes, ${ }^{22}$ resulting in mitochondrial dysfunction. ${ }^{23-25}$ Moreover, recent evidence has shown that oxidative stress is responsible for opening mitochondrial permeability transition pore (mPTP), ${ }^{26,27}$ leading to myocardial injuries and cell death..$^{27,28}$

Mitochondrial has been known to mediate cell death upon oxidative damages via a series of apoptotic signaling cascades by releasing cytochrome $\mathrm{C}$ and/or apoptosis inducing factor (AIF) from mitochondria. This triggers caspase-dependent and/or -independent apoptosis, respectively. ${ }^{29,30}$ For this reason, protection of mitochondria against oxidative stress via mitochondrial antioxidants has been suggested to be a key countermeasure against $\mathrm{I} / \mathrm{R}$-induced myocardial injury owing to the massive production of ROS during I/R.

Two major antioxidative defence systems in mitochon- dria exist to work as a unit to eliminate oxidative stress: 1) manganese superoxide dismutase (MnSOD) and 2) glutathione peroxidase (GPX), catalase (CAT), and peroxiredoxin III (PRX III).

\section{Removal of Superoxide Radicals}

MnSOD detoxifies superoxide radicals by converting them into hydrogen peroxide $\left(\mathrm{H}_{2} \mathrm{O}_{2}\right)$ and oxygen:

$$
2 \mathrm{O}_{2}^{\cdot-}+2 \mathrm{H}^{+}+\mathrm{MnSOD} \rightarrow \mathrm{H}_{2} \mathrm{O}_{2}+\mathrm{O}_{2}
$$

Thus, in mammalian cells, MnSOD has been considered as an essential antioxidant enzyme responsible for cardioprotection. ${ }^{31}$ Indeed, multilayers of evidence have demonstrated that partial downregulation or complete knockdown of MnSOD accelerates myocardial injuries under oxidative stress, ${ }^{32,33}$ while upregulation of MnSOD minimizes infarct size of the heart undergoing an $\mathrm{I} / \mathrm{R}$ insult. ${ }^{34}$

\section{Removal of $\mathrm{H}_{2} \mathrm{O}_{2}$}

Relatively stable $\mathrm{H}_{2} \mathrm{O}_{2}$ produced from the process of dismutation of superoxide radicals by MnSOD in the mitochondria is considered to be potentially harmful because it can becomea highly reactive hydroxyl radical $(\mathrm{OH})$ in the presence of $\mathrm{Fe}^{2+}$ via Fenton reaction:

$$
\mathrm{Fe}^{+2}+\mathrm{H}_{2} \mathrm{O}_{2} \rightarrow \mathrm{Fe}^{+3}+\mathrm{OH}+\mathrm{OH}^{-}
$$

In fact, $\mathrm{H}_{2} \mathrm{O}_{2}$ compared to charged superoxide radicals can be freely diffused across membranes and become a source of hydroxyl radicals. Recent evidence indicates that $\mathrm{H}_{2} \mathrm{O}_{2}$ not only causes a collapse of mitochondrial membrane potential by opening MPTP but also induces protein oxidation of sarcoplasmic reticulum $\mathrm{Ca}^{2+}$ ATPase, potentially leading to mitochondrial $\mathrm{Ca}^{2+}$ overload. Therefore, this oxidant can also initiate apoptosis. Due to this deleterious effect, endogenous antioxidants (e.g., GPX, CAT, and PRX III) specifically targeting $\mathrm{H}_{2} \mathrm{O}_{2}$ in mitochondria exist.

\section{GPX, CAT, and PRX III}

As shown in Figure 1, GPX, CAT, and PRX III function as a unit to remove $\mathrm{H}_{2} \mathrm{O}_{2}$. Briefly, GPX is thiol-containing peroxidase and uses glutathione (GSH) as a reducing equivalent to reduce $\mathrm{H}_{2} \mathrm{O}_{2}$ to form oxidized glutathione (GSSG) and water. Similarly, a hemecontaining homotetrametic enzyme, CAT, converts $\mathrm{H}_{2} \mathrm{O}_{2}$ to water and oxygen. A recent study has shown that mitochondria-targeted CAT in a mouse experimental model significantly increases life span, ${ }^{35}$ whereas mutation of this enzyme exhibits more susceptibility to oxidative damage. ${ }^{36}$ Recently, PRX III have received special attention because this enzyme exerts potent antioxidative roles in the cells, ranging from degradation of $\mathrm{H}_{2} \mathrm{O}_{2}$ and repair of membrane lipid to modification of apoptosis induction. ${ }^{37}$ Indeed, it has been reported that PRXIII is the most abundant and efficient antioxidant enzyme targeting $\mathrm{H}_{2} \mathrm{O}_{2}$ in mitochondria. ${ }^{38}$ PRX III neutralizes $\mathrm{H}_{2} \mathrm{O}_{2}$ produced in mitochondria through their peroxidase activity with the use of electrons provided by thioredoxin II (TRX II) that is reduced by NADPH via thioredoxin reductase (TRX R II). ${ }^{39-41}$ 


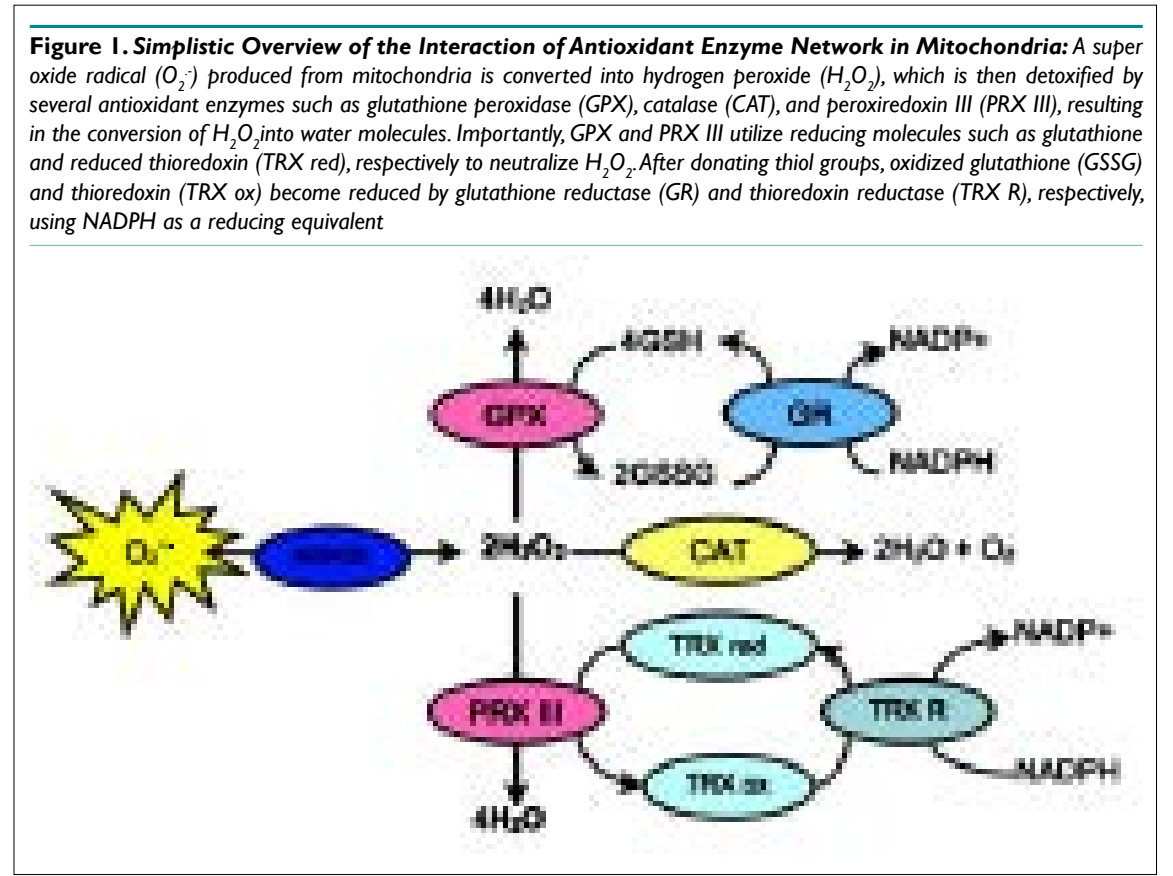

\section{EXERCISE-INDUCED CARDIOPROTECTION AGAINST AN I/R INSULT: ROLE OF MNSOD |}

Endurance exercise has been demonstrated to reduce myocardial injury against $\mathrm{I} / \mathrm{R}$ injuries including contractile function and myocardial infarction size. ${ }^{42-46}$ While several cardioprotective mechanisms induced by endurance exercise have been proposed (eg, reduced calcium overload, heat shock proteins, and increased ATP-dependent potassium channels), an increase in antioxidant capacity has been recognized as a key mechanism. Indeed, given that $\mathrm{I} / \mathrm{R}$ contribute to massive ROS production, the notion that enhanced antioxidative capacity in response to exercise is associated with cardioprotection is not surprising. Growing evidence has shown that increased activities of manganese MnSOD are linked to exercise-induced cardioprotection. . $^{24,43,47,48}$ This crucial role of MnSOD in cardioprotection was strongly supported by a recent study in which knockdown of exercise-induced MnSOD expression via in vivo administration of an antisense oligodeoxyribonucleotide against MnSOD significantly diminished exercise-mediated cardioprotection. ${ }^{47}$ Despite this clear association of increased MnSOD with cardioprotection, mechanisms of how endurance exercise increases MnSOD has not been clearly elucidated yet.

Nonetheless, according to recent research, a transcription factor, cAMP-responsive element binding protein (CREB), is linked to regulate MnSOD expression. ${ }^{49,50}$ Also, another transcription factor, tumor necrosis factor- $\alpha$ (TNF- $\alpha$ ), has been reported to induce MnSOD gene expression and plays an important role in cardioprotective role against an IR insult, as the cardioprotection was abolished when TNF- $\alpha$ was absent. ${ }^{51}$ This observation appears to indicate that a TNF- $\alpha$ signaling may be a potential mechanism of exercise-induced MnSOD upregulation; however, given that endurance exercise rather reduces inflammatory cytokines including TNF- $\alpha,{ }^{52,53}$ this signaling pathway is less likely to be the case. Another potential mechanism involved in enhancing MnSOD activities is the nuclear erythroid-2 like factor-2 (NRF2), known as a master transcription regulator of various antioxidant enzymes. ${ }^{54}$ In support of this notion, recent studies have reported that NRF2mediated heme oxygenase-1 (HO-1) upregulation in the heart enhances MnSOD activities via carbon monoxide production upon HO-1 potentiation. ${ }^{55}$ Currently, whether this notion is applicable to endurance, exercise-induced cardioprotection remain enigmatic because long-term endurance exercise impairs NRF2 signaling, resulting in cardiac dysfunction, ${ }^{56}$ whereas moderate intensity endurance exercise improves cardiac oxidative stress via upregulation of NRF2 expression. ${ }^{57}$ Therefore, further mechanistic studies are needed to determine the functional role of NRF2 in MnSOD regulation and involvement in exercise-induced cardioprotection.

\section{EXERCISE-INDUCED CARDIOPROTECTION AGAINST AN I/R INSULT: ROLE OF GPX, CAT, AND PRX III /-}

As previously described, removal of superoxide radicals by $\mathrm{Mn}$ SOD results in the production of another form of ROS, $\mathrm{H}_{2} \mathrm{O}_{2}$. Thus, increased MnSOD expression or activities in response to endurance exercise can cause a potential source of oxidative stress in mitochondria. Regarding this notion, recent studies have shown that endurance exercise upregulates GPX in the mitochondria in parallel with reduced $\mathrm{H}_{2} \mathrm{O}_{2}$ production and mitochondrial lipid peroxidation. ${ }^{24}$ Interestingly, Starnes et al did not observe an increase in GPX, but showed that CAT was increased in response to short-term endurance exercise. ${ }^{58}$ Consistent with this study, a study by Moran et al also showed that 12 weeks of endurance training does not modulate GPX in rat's myocardium. ${ }^{59}$ Currently, it remains unknown why GPX responds differently to exercise training; but a study led by Ji group seems to provide a potential answer. His research group showed that modulation of antioxidant levels in response to endurance exercise appears to be tissue-specific, with highly oxidative tissues such as soleus and heart showing no significant alteration and rather reduction in some cases. ${ }^{60}$

It is surprising that despite a potent antioxidative role 


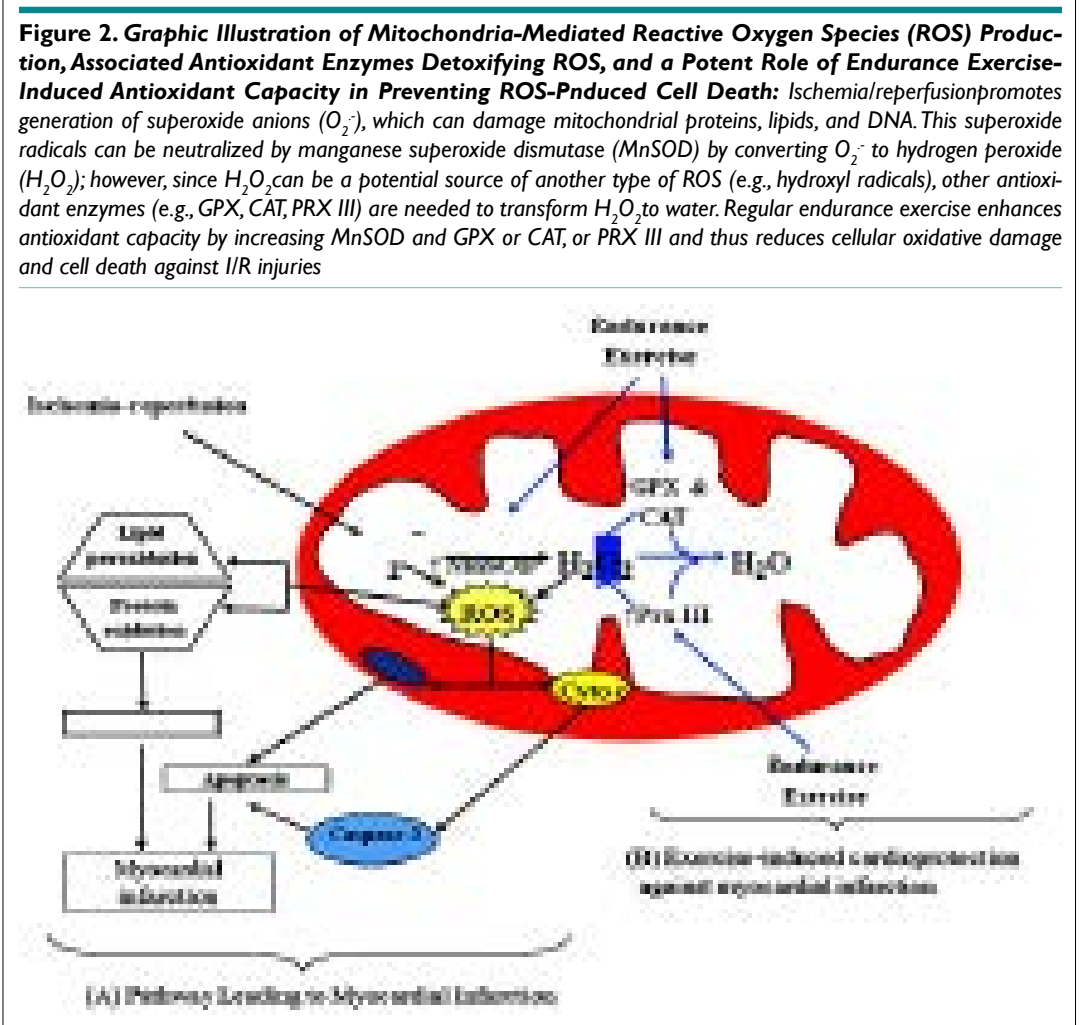

of PRX III against oxidative stress, very little studies have been conducted. Currently, only one study is available, demonstrating that PRX III levels were elevated in mitochondria by endurance exercise, ${ }^{61}$ suggesting that this phenotypic change may be linked to cardiac protection against oxidative stress.

\section{SUMMARY}

It is well known that oxidative stress during an I/R episode contributes to myocardial infarction, and thus improved antioxidative capacity has been suggested to reduce myocardial infarction. Similarly, a non-pharmacological intervention, endurance exercise, has been reported to improve endogenous antioxidant capacity, leading to cardioprotection against an I/R insult. Given that mitochondrial are major sources of ROS production and become a potent initiator of cell death under stressed conditions such as an I/R insult, mitochondria-specific antioxidant enzymes have emerged as a potential strategy that reduces oxidative stress and infarction. In mitochondria, MnSOD converts superoxide into weak oxidant $\mathrm{H}_{2} \mathrm{O}_{2}$, which is then detoxified by GPX or CAT, or PRX III, resulting in the production of oxygen and water. Both classical and recent studies have shown that endurance exercise-induced improvement in MnSOD, GPX, CAT, and PRX III is associated with cardioprotection against $\mathrm{I} / \mathrm{R}$ injuries by reducing both apoptosis and necrosis (Figure 2). However, how regular endurance exercise upregulates these antioxidant enzymes has not been clearly elucidated yet although some transcription factors (e.g., CREB, TNF- $\alpha$, and NRF2) has been indicated as plausible candidates. Therefore, identification of clear signaling pathways of exercise-induced antioxidant upregulation will provide key insight into developing a pharmacological therapeutic strategy against myocardial infarction.

\section{ACKNOWLEDGEMENT}

This project was supported by a research grant from the University of West Florida though Office of Research and Sponsored Programs (R0062) and UWF Florida Research Fellowship to YL (CF6672 and CR0070).

\section{CONFLICTS OF INTEREST}

The authors declare that they have no conflicts of interest.

\section{REFERENCES}

1. Downey JM. Free radicals and their involvement during longterm myocardial ischemia and reperfusion. Annu Rev Physiol. 1990; 52: 487-504. doi: 10.1146/annurev.ph.52.030190.002415

2. Duerr GD, Dewald D, Schmitz EJ, et al. Metallothioneins 1 and 2 modulate inflammation and support remodeling in ischemic cardiomyopathy in mice. Mediators of inflammation. 2016; 2016: 7174127. doi: 10.1155/2016/7174127

3. Lund J, Hafstad AD, Boardman NT, et al. Exercise training promotes cardioprotection through oxygen-sparing action in high fatfed mice. Am J Physiol Heart Circ Physiol. 2015; 308(8): H823-H829. doi: 10.1152/ajpheart.00734.2014

4. Woodall MC, Woodall BP, Gao E, Yuan A, Koch WJ. Cardiac fibroblast GRK2 deletion enhances contractility and remodeling following ischemia/reperfusion injury. Circ Res. 2016; 119(10): 1116-1127. doi: 10.1161/CIRCRESAHA.116.309538 
5. Zhou Y, Fang H, Lin S, et al. Qiliqiangxin protects against Cardiac ischemia-reperfusion injury via activation of the mTOR pathway. Cell Physiol Biochem. 2015; 37(2): 454-464. doi: 10.1159/000430368

6. Dauerman HL, Bates ER, Kontos MC, et al. Nationwide analysis of patients with ST-segment-elevation myocardial infarction transferred for primary percutaneous intervention: Findings from the American Heart Association mission: Lifeline program. Circ Cardiovasc Interv. 2015; 8(5). doi: 10.1161/CIRCINTERVENTIONS.114.002450

7. Harrison RW, Simon D, Miller AL, de Lemos JA, Peterson ED, Wang TY. Association of hospital myocardial infarction volume with adherence to American College of Cardiology/American Heart Association performance measures: Insights from the $\mathrm{Na}$ tional Cardiovascular Data Registry. Am Heart J. 2016; 178: 95-101. doi: 10.1016/j.ahj.2016.04.002

8. Boveris A. Determination of the production of superoxide radicals and hydrogen peroxide in mitochondria. Methods Ensymol. 1984; 105: 429-435. doi: 10.1016/S0076-6879(84)05060-6

9. Li C, Jackson RM. Reactive species mechanisms of cellular hypoxia-reoxygenation injury. Am J Physiol Cell Physiol. 2002; 282(2): C227-C241. doi: 10.1152/ajpcell.00112.2001

10. McCord JM. Oxygen-derived free radicals in postischemic tissue injury. N Engl J Med. 1985; 312(3): 159-163. doi: 10.1056/ NEJM198501173120305

11. Yu BP. Cellular defenses against damage from reactive oxygen species. Physiol Rev. 1994; 74(1): 139-162. doi: 10.1152/physrev.1994.74.1.139

12. Cadenas S. ROS and redox signaling in myocardial ischemiareperfusion injury and cardioprotection. Free Radic Biol Med. 2018; 117: 76-89.

13. Groehler At, Kren S, Li Q, et al. Oxidative cross-linking of proteins to DNA following ischemia-reperfusion injury. Free Radic Biol Med. 2018; 120: 89-101 doi: 10.1016/j.freeradbiomed.2018.03.010

14. Tian C, Gao L, Zimmerman MC, Zucker IH. Myocardial infarction-induced microRNA-enriched exosomes contribute to cardiac Nrf2 dysregulation in chronic heart failure. Am J Physiol Heart Circ Physiol. 2018; doi: 10.1152/ajpheart.00602.2017

15. Zweier JL, Fertmann J, Wei G. Nitric oxide and peroxynitrite in postischemic myocardium. Antioxid Redox Signal. 2001; 3(1): 11-22. doi: 10.1089/152308601750100443

16. Zhang X, Hu H, Luo J, et al. A novel danshensu-tetramethylpyrazine conjugate DT-010 provides cardioprotection through the PGC-1alpha/Nrf2/HO-1 pathway. Biol Pharm Bull. 2017; 40(9): 1490-1498. doi: 10.1248/bpb.b17-00313

17. Barja G. Mitochondrial oxygen radical generation and leak: sites of production in states 4 and 3 , organ specificity, and relation to aging and longevity. J Bioenerg Biomembr. 1999; 31(4): 347-366. doi: 10.1023/A:1005427919188

18. Lesnefsky EJ, Gudz TI, Moghaddas S, et al. Aging decreases electron transport complex III activity in heart interfibrillar mitochondria by alteration of the cytochrome c binding site. J Mol Cell Cardiol. 2001; 33(1): 37-47. doi: 10.1006/jmcc.2000.1273

19. Hoppel CL, Moghaddas S, Lesnefsky EJ. Interfibrillar cardiac mitochondrial comples III defects in the aging rat heart. Biogerontology. 2002; 3(1-2): 41-44. doi: 10.1023/A:1015251212039

20. Kuksal N, Gardiner D, Qi D, Mailloux RJ. Partial loss of complex I due to NDUFS4 deficiency augments myocardial reperfusion damage by increasing mitochondrial superoxide/hydrogen peroxide production. Biochem Biophys Res Commun. 2018; 498(1): 214-220. doi: 10.1016/j.bbrc.2018.02.208

21. Moris D, Spartalis M, Tzatzaki E, et al. The role of reactive oxygen species in myocardial redox signaling and regulation. Ann Transl Med. 2017; 5(16): 324. doi: 10.21037/atm.2017.06.17

22. Scandroglio F, Tortora V, Radi R, Castro L. Metabolic control analysis of mitochondrial aconitase: influence over respiration and mitochondrial superoxide and hydrogen peroxide production. Free RadicRes. 2014; 48(6): 684-693. doi: 10.3109/10715762.2014.900175

23. Gincel D, Zaid H, Shoshan-Barmatz V. Calcium binding and translocation by the voltage-dependent anion channel: A possible regulatory mechanism in mitochondrial function. Biochem J. 2001; 358(Pt 1): 147-155. doi: 10.1042/bj3580147

24. Lee Y, Min K, Talbert EE, et al. Exercise protects cardiac mitochondria against ischemia-reperfusion injury. Med Sci Sports Exerc. 2012; 44(3): 397-405. doi: 10.1249/MSS.0b013e318231c037

25. Ribeiro Junior RF, Dabkowski ER, Shekar KC, KA OC, Hecker PA, Murphy MP. MitoQ improves mitochondrial dysfunction in heart failure induced by pressure overload. Free Radic Biol Med. 2018; 117: 18-29. doi: 10.1016/j.freeradbiomed.2018.01.012

26. Karch J, Molkentin JD. Identifying the components of the elusive mitochondrial permeability transition pore. Proc Natl Acad Sci U S A. 2014; 111(29): 10396-10397. doi: 10.1073/pnas.1410104111

27. Morciano G, Bonora M, Campo G, et al. Mechanistic role of mPTP in ischemia-reperfusion injury. Adv Exp Med Biol. 2017; 982: 169-189. doi: 10.1007/978-3-319-55330-6_9

28. Kubli DA, Ycaza JE, Gustafsson AB. Bnip3 mediates mitochondrial dysfunction and cell death through Bax and Bak. Biochem J. 2007; 405(3): 407-415. doi: 10.1042/BJ20070319

29. Lee $Y$, Gustafsson AB. Role of apoptosis in cardiovascular disease. Apoptosis. 2009; 14(4): 536-548. doi: 10.1007/s10495-0080302-x

30. Kuo HF, Liu PL, Chong IW, et al. Pigment epithelium-de- 
rived factor mediates autophagy and apoptosis in myocardial hypoxia/reoxygenation injury. PLoS One. 2016; 11(5): e0156059. doi: 10.1371/journal.pone.0156059

31. Yen HC, Oberley TD, Vichitbandha S, Ho YS, St Clair DK. The protective role of manganese superoxide dismutase against adriamycin-induced acute cardiac toxicity in transgenic mice. J Clin Invest. 1996; 98(5): 1253-1260. doi: 10.1172/JCI118909

32. Van Remmen H, Qi W, Sabia M, et al. Multiple deficiencies in antioxidant enzymes in mice result in a compound increase in sensitivity to oxidative stress. Free Radic Biol Med. 2004; 36(12): 1625 1634. doi: 10.1016/j.freeradbiomed.2004.03.016

33. Van Remmen H, Williams MD, Guo Z, et al. Knockout mice heterozygous for Sod2 show alterations in cardiac mitochondrial function and apoptosis. Am J Physiol Heart Circ Physiol. 2001; 281(3): H1422-1432. doi: 10.1152/ajpheart.2001.281.3.H1422

34. Chen Z, Siu B, Ho YS, et al. Overexpression of MnSOD protects against myocardial ischemia/reperfusion injury in transgenic mice. J Mol Cell Cardiol. 1998; 30(11): 2281-2289. doi: 10.1006/ jmcc.1998.0789

35. Dai DF, Chiao YA, Martin GM, et al. Mitochondrial-targeted catalase: Extended longevity and the roles in various disease models. Prog Mol Biol Transl Sci. 2017; 146: 203-241. doi: 10.1016/ bs.pmbts.2016.12.015

36. Izawa S, Inoue Y, Kimura A. Importance of catalase in the adaptive response to hydrogen peroxide: Analysis of acatalasaemic saccharomyces cerevisiae. Biochem J. 1996; 320 ( Pt 1): 61-67. doi: 10.1042/bj3200061

37. Wood ZA, Poole LB, Karplus PA. Peroxiredoxin evolution and the regulation of hydrogen peroxide signaling. Science. 2003; 300(5619): 650-653. doi: 10.1126/science.1080405

38. Rhee SG, Kil IS. Mitochondrial $\mathrm{H}_{2} \mathrm{O}_{2}$ signaling is controlled by the concerted action of peroxiredoxin III and sulfiredoxin: Linking mitochondrial function to circadian rhythm. Free Radic Biol Med. 2016; 100: 73-80. doi: 10.1016/j.freeradbiomed.2016.07.029

39. Hofmann B, Hecht HJ, Flohe L. Peroxiredoxins. Biol Chem. 2002; 383(3-4): 347-364.

40. Kinnula VL, Lehtonen S, Sormunen R, et al. Overexpression of peroxiredoxins I, II, III, V, and VI in malignant mesothelioma. J Pathol. 2002; 196(3): 316-323. doi: 10.1002/path.1042

41. Seaver LC, Imlay JA. Alkyl hydroperoxide reductase is the primary scavenger of endogenous hydrogen peroxide in escherichia coli. J Bacteriol. 2001; 183(24): 7173-7181. doi: 10.1128/ JB.183.24.7173-7181.2001

42. Brown DA, Jew KN, Sparagna GC, Musch TI, Moore RL. Exercise training preserves coronary flow and reduces infarct size after ischemia-reperfusion in rat heart. J Appl Physiol. 2003; 95(6):
2510-2518. doi: 10.1152/japplphysiol.00487.2003

43. Hamilton KL, Powers SK, Sugiura T, et al. Short-term exercise training can improve myocardial tolerance to $\mathrm{I} / \mathrm{R}$ without elevation in heat shock proteins. Am J Physiol Heart Circ Physiol. 2001; 281(3): H1346-H1352. doi: 10.1152/ajpheart.2001.281.3.H1346

44. Lennon SL, Quindry JC, Hamilton KL, et al. Elevated MnSOD is not required for exercise-induced cardioprotection against myocardial stunning. Am J Physiol Heart Circ Physiol. 2004; 287(2): H975-H980. doi: 10.1152/ajpheart.01208.2003

45. Li Y, Cai M, Cao L, et al. Endurance exercise accelerates myocardial tissue oxygenation recovery and reduces ischemia reperfusion injury in mice. PLoS One. 2014; 9(12): e114205. doi: 10.1371/ journal.pone.0114205

46. Quindry JC, Hamilton KL, French JP, et al. Exercise-induced HSP-72 elevation and cardioprotection against infarct and apoptosis. J Appl Physiol (1985). 2007; 103(3): 1056-1062. doi: 10.1152/ japplphysiol.00263.2007

47. Hamilton KL, Quindry JC, French JP, et al. MnSOD antisense treatment and exercise-induced protection against arrhythmias. Free Radic Biol Med. 2004; 37(9): 1360-1368. doi: 10.1016/j.freeradbiomed.2004.07.025

48. Yamashita N, Hoshida S, Otsu K, Asahi M, Kuzuya T, Hori M. Exercise provides direct biphasic cardioprotection via manganese superoxide dismutase activation. J Exp Med. 1999; 189(11): 16991706. doi: $10.1084 /$ jem.189.11.1699

49. Chung YW, Kim HK, Kim IY, Yim MB, Chock PB. Dual function of protein kinase $\mathrm{C}$ (PKC) in 12-O-tetradecanoylphorbol-13-acetate (TPA)-induced manganese superoxide dismutase (MnSOD) expression: Activation of CREB and FOXO3a by PKC-alpha phosphorylation and by PKC-mediated inactivation of Akt, respectively. J Biol Chem. 2011; 286(34): 29681-29690. doi: 10.1074/jbc.M111.264945

50. Watson PA, Birdsey N, Huggins GS, Svensson E, Heppe D, Knaub L. Cardiac-specific overexpression of dominant-negative CREB leads to increased mortality and mitochondrial dysfunction in female mice. Am J Physiol Heart Circ Physiol. 2010; 299(6): H2056H2068. doi: 10.1152/ajpheart.00394.2010

51. Eddy LJ, Goeddel DV, Wong GH. Tumor necrosis factoralpha pretreatment is protective in a rat model of myocardial ischemia-reperfusion injury. Biochem Biophys Res Commun. 1992; 184(2): 1056-1059. doi: 10.1016/0006-291X(92)90698-K

52. Pedersen BK. The anti-inflammatory effect of exercise: Its role in diabetes and cardiovascular disease control. Essays Biochem. 2006; 42: 105-117. doi: 10.1042/bse0420105

53. Petersen AM, Pedersen BK. The anti-inflammatory effect of exercise. J Appl Physiol (1985). 2005; 98(4): 1154-1162. doi: 


\subsection{2/japplphysiol.00164.2004}

54. Smith RE, Tran K, Smith CC, McDonald M, Shejwalkar P, Hara K. The role of the Nrf2/ARE antioxidant system in preventing cardiovascular diseases. Diseases. 2016; 4(4). doi: 10.3390/diseases 4040034

55. Piantadosi CA, Carraway MS, Babiker A, Suliman HB. Heme oxygenase-1 regulates cardiac mitochondrial biogenesis via Nrf2-mediated transcriptional control of nuclear respiratory factor-1. Circ Res. 2008; 103(11): 1232-1240. doi: 10.1161/01. RES.0000338597.71702.ad

56. Shanmugam G, Narasimhan M, Conley RL, et al. Chronic endurance exercise impairs cardiac structure and function in middleaged mice with impaired Nrf2 signaling. Front Physiol. 2017; 8: 268. doi: 10.3389/fphys.2017.00268

57. Gounder SS, Kannan S, Devadoss D, et al. Impaired transcriptional activity of $\mathrm{Nrf2}$ in age-related myocardial oxidative stress is reversible by moderate exercise training. PLoS One. 2012; 7(9): e45697. doi: 10.1371/journal.pone.0045697
58. Starnes JW, Barnes BD, Olsen ME. Exercise training decreases rat heart mitochondria free radical generation but does not prevent Ca2+-induced dysfunction. J Appl Physiol (1985). 2007; 102(5): 1793-1798. doi: 10.1152/japplphysiol.00849.2006

59. Moran M, Delgado J, Gonzalez B, Manso R, Megias A. Responses of rat myocardial antioxidant defences and heat shock protein HSP72 induced by 12 and 24-week treadmill training. Acta Physiol Scand. 2004; 180(2): 157-166. doi: 10.1111/j.00016772.2003.01244.x

60. Leeuwenburgh C, Hollander J, Leichtweis S, Griffiths M, Gore M, Ji LL. Adaptations of glutathione antioxidant system to endurance training are tissue and muscle fiber specific. Am J Physiol. 1997; 272(1 Pt 2): R363-R369. doi: 10.1152/ajpregu.1997.272.1.R363

61. Kavazis AN, Alvarez S, Talbert E, Lee Y, Powers SK. Exercise training induces a cardioprotective phenotype and alterations in cardiac subsarcolemmal and intermyofibrillar mitochondrial proteins. Am J Physiol Heart Circ Physiol. 2009; 297(1): H144-H152. doi: 10.1152/ajpheart.01278.2008 